\title{
Contents of Volume 1
}

Auer, J., see A. Franz

Balevski, D., The influence of the work of the Conference of European Statisticians on the statistical activity of the Committee for a Unified System of Social Information (to the Council of Ministers) of the People's Republic of Bulgaria

Balk, B.M. and H.W.J. Donkers, Adjusting the consumer price index for changes of the rates of indirect taxes and subsidies

Belov, N., Training of staff in the use of EDP technology for the processing of statistical information - USSR experience

Bethlehem, J.G. and H.M.P. Kersten, Non-response in Dutch sample surveys 253

Bjerve, P.J., Three decades of the Conference of European Statisticians: past achievements and perspectives for the future

Conference of European Statisticians

- a survey

The work of the - in the field of electronic data processing 55

Main features of the work by the - on economic statistics 61

The work of the - in the field of social and demographic statistics 75

Forthcoming meetings convened by the -

$117,273,369$

List of documents issued

July 1980-June 1981

July 1981-June 1982

Recent work

Cwil, E., see A. Franz

Donkers, H.W.J., see B.M. Balk

ECE, The contribution of the Statistical Division to empirical studies undertaken by the ECE secretariat

The ECE's statistical publication programme

Enterprise statistics in countries with centrally planned economies

Environment and energy statistics - past achievements and current status, Work on

Fastbom, L., Regionalization of statistical activities - problems and new technical possibilities

Franz, A., J. Auer, E. Cwil, J. Gawronski, E. Krzeczkowska, and R. Schwarzl, Comparison of prices and levels of gross domestic expenditure between Austria and Poland (APC), 1975 and 1978

Gawronski, J., see A. Franz

Health accounts 
Hoffmann, E., Problems and techniques of harmonizing manpower statistics from different sources - Norwegian experiences

Jeays, T.M., Computer aspects of the use of registers in statistical offices 463

Jensen, J.B., Comparison of retail price indices with and without indirect taxes

Jensen, P., Towards a register-based statistical system - some Danish experience

Kelly, J.J., and C. Walker, Migration between Canada and the United Kingdom: a comparison of unadjusted and adjusted data

Kersten, H.M.P., see J.G. Bethlehem

Krzeczkowska, E., see A. Franz

Lehto, A.-M., see H. Salmi

Lönnberg, O., see H. Salmi

Malinvaud, E., An assessment of 30 years of joint endeavour in the Conference of European Statisticians

Malinvaud, E., From statistics to data management - the French difficulties 285

The Norwegian system of resource accounts 445

Olenski, J., Semantic structures of statistical meta-data 477

Polfeldt, Th., Statistics of the natural environment - aims and methods 407

Rapport, D.J., The stress-response environmental statistical system and its applicability to the Laurentian Lower Great Lakes

Salapa, I., Methods used to obtain high quality, timeliness and reliability of statistical information

Salmi, H., A.-M. Lehto, O. Lönnberg, and H. Sauli, Measuring flows in Finnish manpower statistics

Sauli, H., see H. Salmi

Schwarzl, R., see A. Franz

Swensson, B., A survey of nonresponse terms

Vries, W.F.M. de, Co-ordination as an instrument to improve the quality of statistics

Walker, C., see J.J. Kelly

Weber, J.-L., The French natural patrimony accounts 